ISSN 1420-3049

www.mdpi.com/journal/molecules

\title{
Article
}

\section{Neuroprotective Effects of Exogenous Activin A on Oxygen-Glucose Deprivation in PC12 Cells}

\author{
Jin-Ting He ${ }^{1}$, Jing Mang ${ }^{1}$, Chun-Li Mei ${ }^{1,2}$, Le Yang ${ }^{3}$, Jiao-Qi Wang ${ }^{1}$, Ying Xing ${ }^{1}$, \\ Hong Yang ${ }^{1}$ and Zhong-Xin $\mathrm{Xu}{ }^{1}$ *
}

1 Department of Neurology, China-Japan Friendship Hospital, Jilin University, Changchun 130012, China; E-Mails: Hejinting333@gmail.com (J.-T.H.); Mangjing505@sina.com (J.M.); wangjiaoqi111@sina.com (J.-Q.W.); xingying333@sina.com (Y.X.); yanghong555@sina.com (H.Y.)

2 College of Nursing, Beihua University, Jilin 132013, China; E-Mail: meixiaoqing2007@126.com

3 People's Hospital of Jilin Province, Changchun 130021, China; E-Mail:Yangle800511@sina.com

* Author to whom correspondence should be addressed; E-Mail: xuzhongxin999@yahoo.com.cn; Tel.: +86-431-8464-5107; Fax: +86-431-8464-5107.

Received: 6 December 2011; in revised form: 19 December 2011 / Accepted: 22 December 2011 / Published: 30 December 2011

\begin{abstract}
Ischemic cerebrovascular disease is one of the most common causes of death in the World. Exogenous activin A (ActA) protects neurons against toxicity and plays a central role in regulating the brain's response to injury. In the present study, we investigated the mechanisms involved in the neuroprotective effects of ActA in a model of hypoxic-ischemic brain disease. We found that ActA could effectively increase the survival rate of $\mathrm{PC} 12$ cells and relieve oxygen-glucose deprivation (OGD) damage. To clarify the neuroprotective mechanisms of ActA, the effects of ActA on the ActA/Smad pathway and on the up-regulation of inducible nitric oxide synthase (NOS) and superoxide dismutase (SOD) were investigated using OGD in PC12 cells. The results showed that ActA could increase the expression of activin receptor IIA (ActRIIA), Smad3 and Smad4 and that $50 \mathrm{ng} / \mathrm{mL}$ and $100 \mathrm{ng} / \mathrm{mL}$ of ActA could reduce NO levels and increase SOD activity by $78.9 \%$ and $79.9 \%$, respectively. These results suggested that the neuroprotective effects of ActA in ischemia could be related to the activation of the ActA/Smad signaling pathway and to its anti-oxidant activities.
\end{abstract}

Keywords: OGD; tolerance model; exogenous activin A 


\section{Introduction}

Ischemic stroke occurs when the blood supply to the brain is obstructed, and it is one of the most common causes of health problems, disability and death in the World. Accumulating evidence suggests that the cell death observed during the first few hours of cerebellar ischemia is a result of apoptosis as opposed to necrosis, which was considered the predominant form of cerebellar damage generated by ischemia [1]. Moreover, the ischemic damage of nerve cells leads to the disruption of a series of complex signaling pathways that produces an effect on corresponding biological functions and affects the function of the brain; this terminal differentiated profile of the brain is of particular relevance for cerebellar ischemia [2-4]. Therefore, it is important to develop therapies that enhance the neuroprotective effects by inhibiting the mechanisms that lead to apoptosis and excessive cell death, before the process becomes irreversible.

Activins are the members of the transforming growth factor (TGF)- $\beta$ superfamily, a group of multifunctional cytokines that regulate cell proliferation, differentiation and death [5]. These biologically active proteins are formed by the homo-or heterodimerization of two (activin) subunits to produce activin $\mathrm{A}(\mathrm{bA} / \mathrm{bA})$, activin $\mathrm{B}(\mathrm{bB} / \mathrm{bB})$ or activin $\mathrm{AB}(\mathrm{bA} / \mathrm{bB})[6]$. As multifunctional growth factors, the roles of the activins extend beyond the scope of the endocrine system and include the control of growth, development, immune function and other cellular processes [7]. Recent reports revealed a crucial role for ActA in inflammatory and repair processes involved in wound healing and brain injury [8]. ActA plays a central role in regulating the brain's response to injury and has a significant protective effects $[9,10]$.

The PC12 cell line is widely used as a model for dopaminergic neuronsm, because it possesses intracellular substrates for the synthesis, metabolism and transportation of dopamine (DA) [11]. An OGD-damage model is one of the more commonly used models for the study of cerebral ischemia. The principle of the OGD model is that $\mathrm{Na}_{2} \mathrm{~S}_{2} \mathrm{O}_{4}$ quickly clears the oxygen in the culture matrix, does not damage the cell membrane and is better able to simulate the hypoxic environment when compared to the in vivo model [12]. In this study, the OGD of PC12 cells was used to establish a cerebral hypoxia-ischemia model. In addition, we measured the amount of NO and the induction of SOD in an attempt to elucidate possible mechanisms that underlie ActA-mediated protection against OGD in PC12 cells.

\section{Results}

\subsection{Effects of ActA on Cell Proliferation}

The cytotoxicity of OGD for $6 \mathrm{~h}$ and ActA plus OGD for $6 \mathrm{~h}$ treatments were determined by examining their effects on the proliferation of PC12 cells. PC12 cells were treated with 10, 20, 30, 50 and $100 \mathrm{ng} / \mathrm{mL}$ ActA for $24 \mathrm{~h}$ before OGD for $6 \mathrm{~h}$ (Figure 1). MTT assays showed that treatment with OGD for $6 \mathrm{~h}$ effectively inhibited the growth of PC12 cells by $25.61 \%$. Compared to the OGD for 6 h-treated group, the ActA plus OGD for 6 h-treated group inhibited the growth of PC12 cells by $19.82 \%, 16.31 \%, 10.36 \%, 5.41 \%$ and $4.92 \%$, in dose-dependent manner, and the survival rates were higher than in the OGD for $6 \mathrm{~h}$-treated group. Because there was no significant difference 
$(p>0.05)$ between the survival rates of the 50 and $100 \mathrm{ng} / \mathrm{mL}$ ActA-treated cells, $50 \mathrm{ng} / \mathrm{mL}$ ActA was used in all subsequent experiments.

Figure 1. MTT assay showing the growth inhibition of PC12 cells treated with ActA for $24 \mathrm{~h}$ plus OGD for $6 \mathrm{~h}$. The cells were grown to a density of $5 \times 10^{4}$ cells per well in a 96-well plate for $24 \mathrm{~h}$. The results show the growth of PC12 cells following incubation in 96-well plates for $24 \mathrm{~h}$ with 10, 20, 30, 50 and $100 \mathrm{ng} / \mathrm{mL}$ ActA plus OGD for $6 \mathrm{~h}$, compared with OGD for $6 \mathrm{~h}$. OGD $6 \mathrm{~h} / \mathrm{ActA}^{-}$denotes a significant difference from the OGD $^{-} /$ActA $^{-}$group $(p<0.05)$; OGD $6 \mathrm{~h} /$ ActA $50 \mathrm{ng} / \mathrm{mL}$ denotes a significant difference from the OGD $6 \mathrm{~h} /$ ActA $^{-}$group $(p<0.05)$. The data represent the means \pm S.E.M. obtained from three separate experiments that were performed in triplicate.

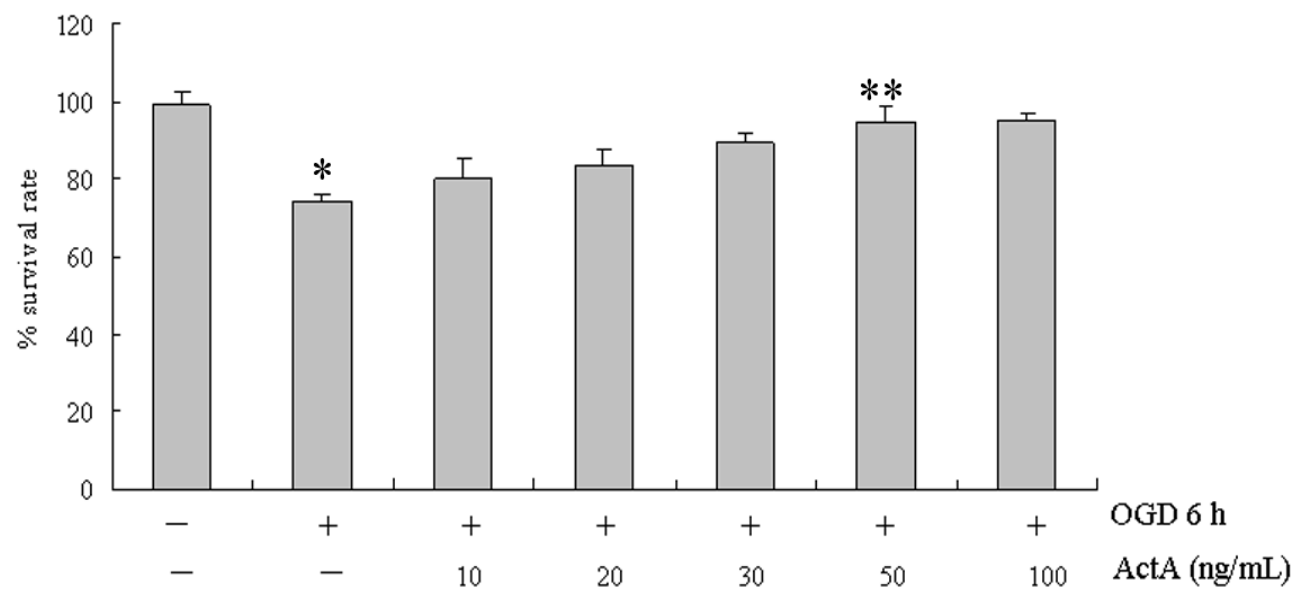

\subsection{ActA Anti-Apoptotic in PC12 Cells}

To assess the apoptosis of differentiated PC12 cells treated with ActA plus OGD and OGD alone, the cells were analyzed using Annexin V-FITC and PI double-staining flow cytometry. The signals from each group of cells are located in the lower right quadrant of the dot-plot graph, and the results are shown in Figure 2. Compared to OGD $6 \mathrm{~h}$, the proportions of apoptotic cells treated with 10, 20, 30, 50 and $100 \mathrm{ng} / \mathrm{mL}$ ActA plus OGD for $6 \mathrm{~h}$ were 10.21\%, 9.27\%, 8.89\%, 6.66\% and, 5.37\%, respectively. In the OGD $6 \mathrm{~h}$ group, the proportions of apoptotic cells was significantly higher than in the $\mathrm{OGD}^{-} / \mathrm{ActA}^{-}$group; the apoptosis rate of the ActA plus OGD for $6 \mathrm{~h}$-treated groups decreased significantly compared to OGD $6 \mathrm{~h}$ group, suggesting that ActA reduce cell damage. Compared with the $50 \mathrm{ng} / \mathrm{mL}$ ActA-treated group, the apoptosis rate of the $100 \mathrm{ng} / \mathrm{mL}$ ActA-treated group was slightly lower.

\subsection{Caspase-3 Activation}

Caspase-3 is widely activated in all major apoptotic signal transduction pathways, we tested pro-caspase-3 after OGD $6 \mathrm{~h}$ and ActA for $24 \mathrm{~h}$. Compared with the $\mathrm{OGD}^{-} / \mathrm{ActA}^{-}$group, the pro-caspase 3, expression levels in PC12 cells increased in the OGD for the 6 h-treated group. Compared with OGD $6 \mathrm{~h}$, the expression levels of pro-caspase- 3 increased in the groups treated with ActA for $24 \mathrm{~h}$ combined with OGD for $6 \mathrm{~h}$ (Figure 3A). To confirm the activity of caspase 3, we measured caspase-3 activities for OGD $6 \mathrm{~h}$ and ActA for $24 \mathrm{~h}$. Compared with the $\mathrm{OGD}^{+} / \mathrm{ActA}^{-}$group, the activities of caspase-3 decreased by treated with ActA for $24 \mathrm{~h}$ combined with OGD for $6 \mathrm{~h}$ (Figure 3B). 
Figure 2. Flow cytometric analysis: assessment of apoptosis. OGD for $6 \mathrm{~h}$ treatment induced apoptosis in PC12 cells and ActA reduced cell damage. The cells were treated with OGD for $6 \mathrm{~h}$ or with different concentrations of ActA plus OGD for $6 \mathrm{~h}$ and were analyzed using flow cytometry following AnnexinV-FITC/PI staining. The data represent from three separate experiments that were performed in triplicate.
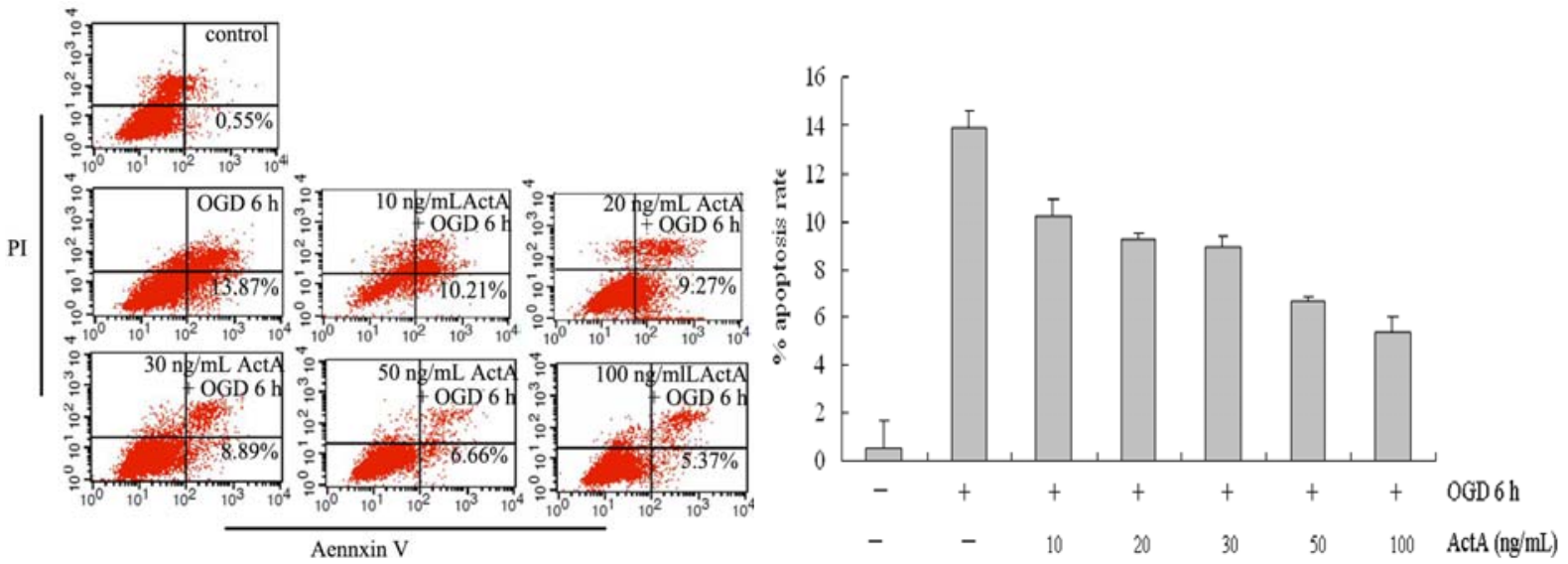

Figure 3. (A) Western blot analysis. PC12 cells were treated OGD $6 \mathrm{~h}$ and ActA for $24 \mathrm{~h}$. Pro-capsase-3 expressions were determined by western blotting. The results are showed in representative of three repeated experiments. NIH imaging indicated that the protein signal densities were higher in $\mathrm{OGD}^{+} / \mathrm{ActA}^{+}$group treated than in $\mathrm{OGD}^{+} / \mathrm{ActA}^{-}$group; (B) Effects of ActA on caspase-3 activity in PC12 cells. The cells were treated OGD $6 \mathrm{~h}$ and ActA for $24 \mathrm{~h}$ and analyzed for the activity of caspase-3. OGD $6 \mathrm{~h} / \mathrm{ActA}^{-}$denotes a significant difference from the $\mathrm{OGD}^{-} / \mathrm{ActA}^{-}$group ( $p<0.05$ ); OGD $6 \mathrm{~h} /$ ActA $50 \mathrm{ng} / \mathrm{mL}$ denotes a significant difference from the OGD $6 \mathrm{~h} /$ ActA $^{-}$group $(p<0.05)$. The data represent from three separate experiments that were performed in triplicate.
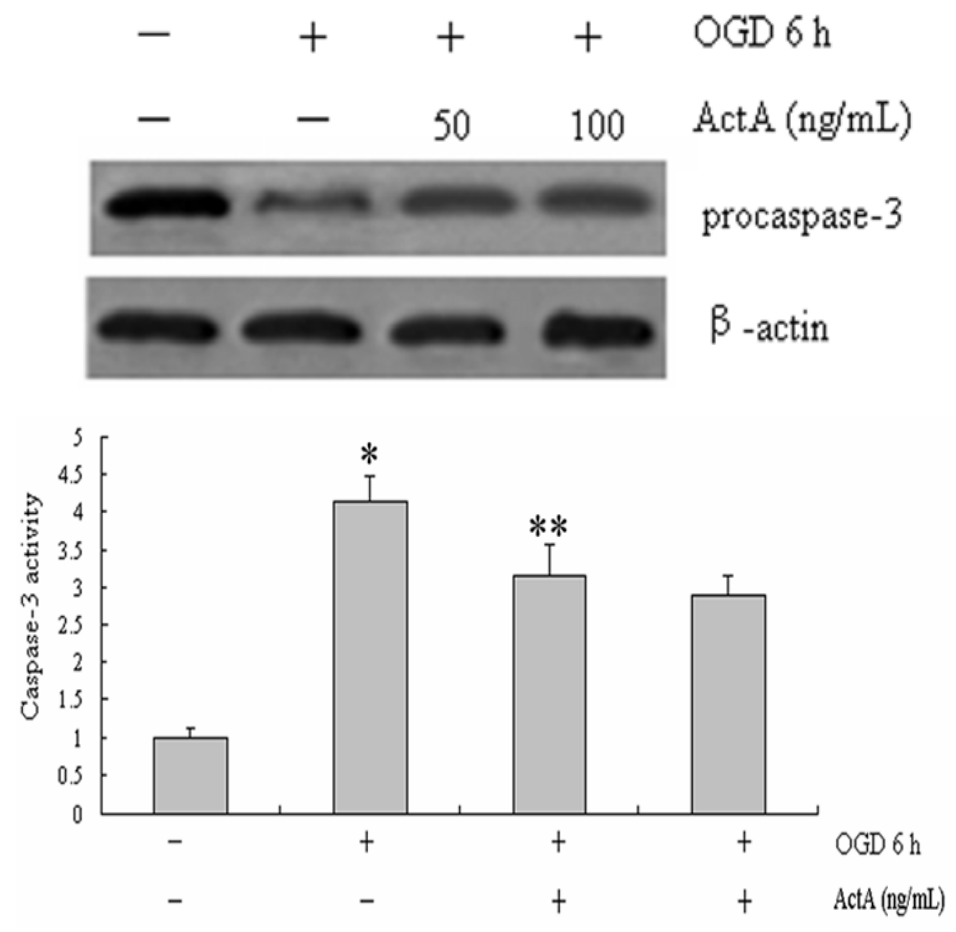

A 


\subsection{Effects of ActA on ActA/Smad Pathway}

The ActA/Smad pathway plays a protective role in ischemia following its activation [13]. To investigate the neuroprotective mechanisms of ActA, the expression of ActRIIA, Smad3 and Smad4 were examined using Western blots (Figure 4). Compared with the $\mathrm{OGD}^{-} / \mathrm{ActA}^{-}$group, the ActRIIA, Smad3 and Smad4 expression levels in PC12 cells increased in the OGD for the 6 h-treated group. Compared with OGD 6 h, the expression levels of ActRIIA, Smad3 and Smad4 increased in the groups treated with ActA for $24 \mathrm{~h}$ combined with OGD for $6 \mathrm{~h}$. In this group, as the concentration of ActA increased, the expression levels of ActRIIA, Smad3 and Smad4 increased in a dose-dependent manner. Therefore, ActA may mediate the neuroprotective effect of the ActA/Smad signaling pathway.

Figure 4. Western blot analysis. PC12 cells were treated with OGD for $6 \mathrm{~h}$ or different concentrations of ActA for $24 \mathrm{~h}$ combined with OGD for $6 \mathrm{~h}$. (A) ActRIIA, Smad3 and Smad4 expression levels were determined using western blots. The results shown are representative of three independent experiments. NIH imaging indicated that the protein signal densities increased in the groups treated with ActA combined with OGD for $6 \mathrm{~h}$ compared with OGD for 6 h-treated groups; (B) ActRIIA, Smad3 and Smad4 protein levels in the groups treated with ActA combined with OGD for $6 \mathrm{~h}$ compared with OGD for 6 h-treated groups. The data represent from three separate experiments that were performed in triplicate.

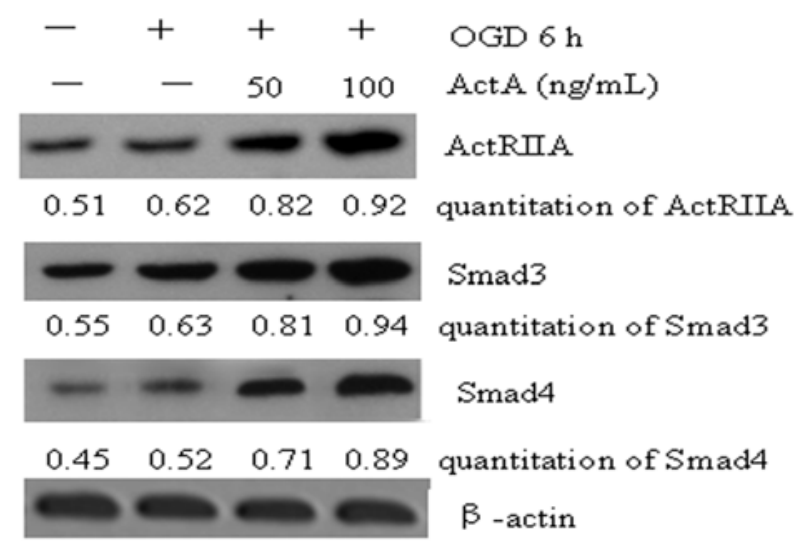

A

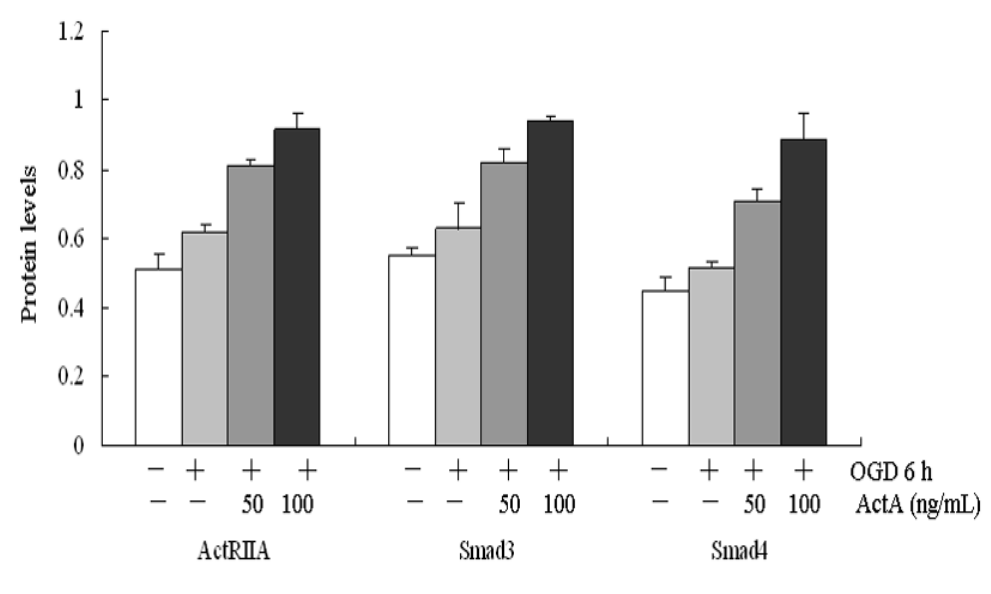




\subsection{Inhibition of NO and $\mathrm{NOS}$ by ActA}

To understand further the neuroprotective mechanisms of ActA, we investigated if ActA could protect PC12 cells from oxidative injury. The cells were treated with OGD for $6 \mathrm{~h}$ or with $50 \mathrm{ng} / \mathrm{mL}$ ActA for $24 \mathrm{~h}$ plus OGD for $6 \mathrm{~h}$, and NO production was assayed by measuring the levels of a stable NO metabolite, nitrites, in the conditioned medium. Incubation with ActA $(50 \mathrm{ng} / \mathrm{mL})$ for $24 \mathrm{~h}$ effectively inhibited NO production in OGD-stimulated PC12 cells (Figure 5A). To determine if the inhibitory effect of ActA on NO production was due to a decrease in NOS protein levels in the cytosol, the levels of NOS protein were examined by Western blot analysis. As shown in Figure 5B, the treatment with $50 \mathrm{ng} / \mathrm{mL}$ ActA resulted in a significant decrease in NOS protein levels.

Figure 5. Effect of ActA on oxidative stress in OGD for 6 h-induced PC12 cells. (A) Cells were OGD-induced by incubation with 50 or $100 \mathrm{ng} / \mathrm{mL}$ of ActA for $24 \mathrm{~h}$ combined with OGD for $6 \mathrm{~h}$. The nitrite content was measured using the Griess reaction. The values indicate the nitrite production in cells that were exposed to the culture supernatants collected from cells that were treated with OGD alone or cells that were exposed to OGD plus ActA. OGD $6 \mathrm{~h} /$ ActA $50 \mathrm{ng} / \mathrm{mL}$ denotes a significant difference from the OGD $6 \mathrm{~h} /$ ActA $^{-}$group $(p<0.05)$. The data represent the means \pm S.E.M. from three independent experiments that were performed in triplicate; $(\mathbf{B})$ Western blot analysis of OGD-induced cells or cells treated with increasing concentrations (50 and $100 \mathrm{ng} / \mathrm{mL}$ ) of ActA for $24 \mathrm{~h}$ combined with OCD for $6 \mathrm{~h}$. The western blot shows the levels of NOS protein expression. $\beta$-actin was used as an internal control. The data represent from three separate experiments that were performed in triplicate.

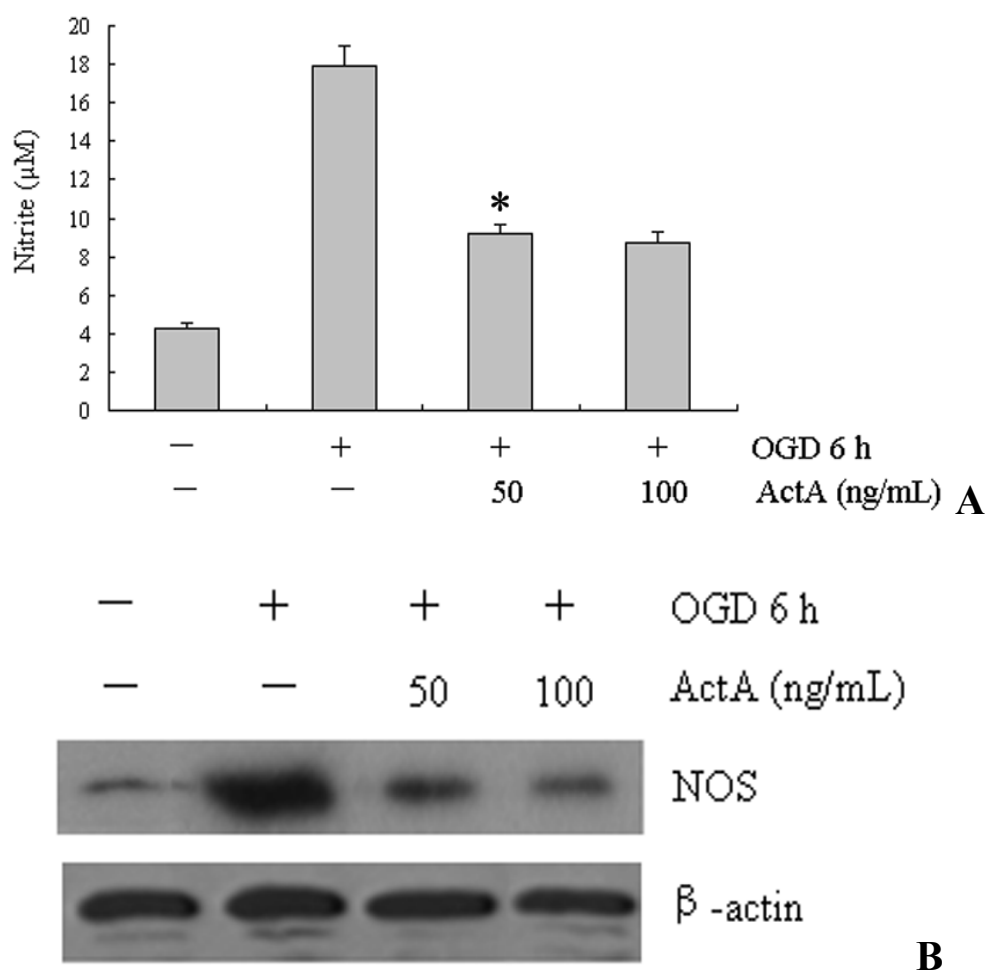




\subsection{Increasing the Activity of SOD by ActA}

The effect of ActA on SOD activity and protein expression were examined (Figure 6). As shown in Figure 6A, compared with the $\mathrm{OGD}^{-} / \mathrm{ActA}^{-}$group, the SOD activity in PC12 cells decreased in the OGD for 6 h-treated group. Compared with the OGD for 6 h-treated group, the SOD activity increased following treatment with different concentrations of ActA for $24 \mathrm{~h}$ combined with OGD for $6 \mathrm{~h}$. Furthermore, the treatment with 50 or $100 \mathrm{ng} / \mathrm{mL}$ ActA led to a significant increase in SOD protein levels (Figure 6B).

Figure 6. The effect of ActA on SOD activity. (A) Cells were OGD-induced or were treated with 50 or $100 \mathrm{ng} / \mathrm{mL}$ of ActA for $24 \mathrm{~h}$ plus OGD for $6 \mathrm{~h}$. The effect of ActA on SOD activity was assessed. OGD $6 \mathrm{~h} /$ ActA $50 \mathrm{ng} / \mathrm{mL}$ denotes a significant difference from the OGD $6 \mathrm{~h} / \mathrm{ActA}^{-}$group $(p<0.05)$. The data represent the means \pm S.E.M. obtained from three independent experiments that were performed in triplicate; (B) Western blot analysis of cells treated with OGD for $6 \mathrm{~h}$ or cells treated with OGD for $6 \mathrm{~h}$ in combination with increasing concentrations (50 and $100 \mathrm{ng} / \mathrm{mL}$ ) of ActA for $24 \mathrm{~h}$. The western blot shows the SOD protein expression. $\beta$-actin was used as an internal control.



\section{Discussion}

Activin A, its receptors, and binding proteins are widely distributed throughout the brain [9]. The models of acute brain injury implicated enhanced activin A expression as a common response to acute neuronal damage of various origins [14]. Hypoxic/ischemic injury, mechanical irritation, and chemical damage of brain evoke a strong upregulation of activin A. Subsequent experimental studies have shown that activin A has a beneficial role to neuronal recovery and that, by activating different pathways, activin A has robust neuroprotective activities [15]. 
In this study, oxygen and glucose deprivation was applied to PC12 cells and the results show that the OGD for 6 h-treated group effectively inhibited the growth of PC12 cells, indicating that the cell model causes cell damage. When compared with the OGD for $6 \mathrm{~h}$-treated group, the ActA plus OGD for $6 \mathrm{~h}$-treated groups effectively increased the survival rate of PC12 cells (Figures 1, 2 and 3). Our results further confirmed the exogenous ActA neuroprotective effect on OGD-induced cell injury which might provide a new method of ischemic cerebrovascular disease treatment.

Activins are members of the transforming growth factor (TGF)- $\beta$ superfamily, it regulated cellular growth and differentiation, control morphogenesis and angiogenesis and repair processes involved in wound healing and brain injury [8], it is possible that when the transmembrane activin receptor (ActR) combines with activin, which subsequently propagates the signal downstream by phosphorylating specific receptor-regulated Smad proteins (R-Smads). Phosphorylated R-Smads form heterocomplexes with the common partner Smad4 (Co-Smad) and translocate to the nucleus where they participate in the regulation of transcription of target genes [16,17] which in turn activates intracellular signal transduction pathways [18]. Smad2, Smad3, a total adjustment type Smad4 and inhibitory Smad7 participate in the ActA/Smad pathway. ActA may combine with ActRII to activate smad2 and $\operatorname{smad} 3$ and to promote the dimerization of smad 4 and $\operatorname{smad} 2 / 3$, which enter the nucleus to influence gene transcription and the activation of a series of biological functions [19]. Our results demonstrate that treatment with OGD for $6 \mathrm{~h}$ increases the expression of ActRIIA, Smad3 and Smad4. When compared to the OGD for 6 h-treated group, ActRIIA, Smad3 and Smad4 expression levels increased following treatment with different concentrations of ActA for $24 \mathrm{~h}$ combined with treatment with OGD for $6 \mathrm{~h}$ (Figure 4). ActA may mediate the ActA/Smad signaling pathway to induce a neuroprotective effect.

The pathogenesis of ischemic cerebrovascular disease is complex and is related to electrolyte imbalances, the production of oxygen free radicals, lipid peroxidation, NO, monoamine neurotransmitters, phospholipid metabolism and the synthesis of other damaging factors [20]. The generation of oxygen-free radicals and NO plays an important role in the promotion of ischemic cerebrovascular disease [21]. Existing animal models are affected by many factors; therefore, a stable cell model of cerebral ischemia was used in this study because the ability to control the experimental conditions, the small amount of sample required and the short experimental period has clear advantages. Many studies indicate that oxidative stress plays a key role in ischemic cerebrovascular disease. SOD plays a vital role in the body's oxidant and antioxidant balance by removing superoxide anion radicals and protecting cells from damage. $\mathrm{NO}$ is an important messenger and effector molecule in vivo, and plays a role in neurotransmitter functions in physiological and pathological events, therefore, SOD and NO are involved in oxidative damage. The results show that OGD significantly increases NO levels and decreases SOD activity, whereas ActA reduces NO levels and increases SOD activity, and this may be the mechanism by which ActA promotes the neuroprotective effect (Figures 5 and 6). Additional in vitro and in vivo studies are necessary to determine whether ActA can be used as a preventive agent against neurodegenerative conditions, or to reduce the progression of chronic and neurodegenerative disorders. 


\section{Experimental}

\subsection{Cell Culture}

PC12 cells were purchased from the Cell Bank of the Chinese Academy of Sciences. The cell line was maintained in DMEM medium supplemented with $10 \%(\mathrm{v} / \mathrm{v})$ fetal bovine serum, $5 \%$ horse serum (FBS, GIBCO), $100 \mathrm{IU} / \mathrm{mL}$ streptomycin, $100 \mathrm{IU} / \mathrm{mL}$ penicillin, $\mathrm{pH}$ 7.0, and the cells were detached using $0.25 \%$ trypsin (Sigma, New York, NY, USA) [22,23]. PC12 cells were grown at $37{ }^{\circ} \mathrm{C}$ in $5 \% \mathrm{CO}_{2}$.

\subsection{OGD for in Vitro Ischemia}

Before differentiation, the cells were grown in 5\% horse serum-containing media on collagen-coated tissue culture dishes. After the cells were attached, they were treated with $100 \mathrm{ng} / \mathrm{mL}$ nerve growth factor (NGF 2.5S; Promega, Madison, WI, USA) and were cultured in serum-free DMEM for 6 days [24]. The cells were washed three times with DMEM and were incubated in DMEM containing 10, 20, 30, 50 and $100 \mathrm{ng} / \mathrm{mL}$ ActA for $24 \mathrm{~h}$. The cells were washed three times with DMEM and were incubated for $6 \mathrm{~h}$ in DMEM containing $1 \mathrm{mmol} / \mathrm{L} \mathrm{NaS}_{2} \mathrm{O}_{4}$ under hypoxic conditions $\left(37{ }^{\circ} \mathrm{C}, 5 \% \mathrm{CO}_{2}\right.$ and $95 \% \mathrm{~N}_{2}$ ) in the absence of sugar [25].

\subsection{Cell Viability Assay}

The MTT method [26] was used to assess the cytotoxic effects of ActA. The cells were grown to a density of $5 \times 10^{4}$ cells/well and were then treated with $10,20,30,50$ and $100 \mathrm{ng} / \mathrm{mL}$ ActA in a 96-well plate for $24 \mathrm{~h}$. At the end of the treatment, the ActA-containing medium was carefully removed and the cells were treated with OGD for $6 \mathrm{~h}$. The culture medium was removed and $200 \mu \mathrm{L}$ medium containing MTT $(20 \mu \mathrm{L}, 5 \mathrm{mg} / \mathrm{mL}$ in PBS, Sigma, St. Louis, MO, USA) was added to each well. After $4 \mathrm{~h}$ of incubation at $37^{\circ} \mathrm{C}$, the medium was removed and DMSO $(100 \mu \mathrm{L})$ was added to each well. The optical absorbance (A) of each well was read at $490 \mathrm{~nm}$. The percentage of viable cells was calculated as follows: (A of experimental group/A of control group) $\times 100 \%$ [27].

\subsection{Flow Cytometry Using Annexin V/PI Staining}

For the quantitative assessment of apoptosis, Annexin V-FITC and PI double staining, followed by flow cytometry was used. The cells were detached using $0.25 \%$ trypsin and harvested, the cells were washed with cold PBS $\left(4{ }^{\circ} \mathrm{C}\right)$ three times and floated by $300 \mu \mathrm{L}$ Binding Buffer $(1 \times)$. The cells were stained by $5 \mu \mathrm{L}$ Annexin V-FITC (Kaiji Bio Co., Nanjing, China) for $15 \mathrm{~min}$ at room temperature in the dark and stained by $5 \mu \mathrm{L}$ PI staining (Kaiji Bio Co., Nanjing, China) for $5 \mathrm{~min}$. Cells were analyzed immediately using flow cytometry. The signals from apoptotic cells are localized in the lower right quadrant of the resulting dot-plot graph [28].

\subsection{Western Blotting Analysis}

After treatment with ActA and OGD for $6 \mathrm{~h}$, the cells were washed twice using cold PBS and $1 \times 10^{6}$ cells were lysed using RIPA buffer [50 mmol/L Tris (pH 8.0), 150 mmol/L NaCl, 0.1\% SDS, 1\% NP40 and $0.5 \%$ sodium deoxycholate] containing protease inhibitors (1\% cocktail and $1 \mathrm{mmol} / \mathrm{L}$ PMSF) $[29,30]$. 
Total proteins were separated using $15 \%$ SDS-PAGE and were transferred to a PVDF membrane. The membrane was blocked using Tris-buffered saline with $0.1 \%$ Tween 20 (pH 7.6, TBST) for $1 \mathrm{~h}$ at room temperature and was incubated with the primary antibody solution $(1: 1,000)$ at $4{ }^{\circ} \mathrm{C}$ overnight. After two washes in TBST, the membrane was incubated with the HRP-labeled secondary antibody (Santa SC-2073) for $1 \mathrm{~h}$ at room temperature and was washed three times with TBST. The final detection was performed using enhanced chemiluminescence (ECL) Western blotting reagents (Amersham Biosciences, Piscataway, NJ, USA) and the membrane was exposed to Lumi-Film Chemiluminescent Detection Film (Roche). Loading differences were normalized using a monoclonal $\beta$-actin antibody. The antibodies used in the study included ActRIIA (Santa, mouse, SC-57022), Smad4 (Santa, rabbit, SC-73040), Smad3 (Santa, rabbit, SC-101154), caspase-3 (Santa, mouse, SC-7272), SOD (Santa, rabbit, SC-18503), NOS (Santa, mouse, SC-49055) and $\beta$-actin (Santa, mouse, SC-2021).

\subsection{Caspase-3 Activation Assays}

Caspase-3 colorimetric assay kits (Kaiji Bio Co., Nanjing, China) were used to investigate caspase-3 in PC12 cells after OGD and ActA treatment, according to the manufacturer's instructions. Briefly, cells were lysed by incubation with cell-lyse buffer on ice for $1 \mathrm{~h}$, and then centrifuged at 10,000 $\mathrm{g}$ for 1 min. Enzymatic reactions were carried out in a 96-well microplate. For each reaction sample, cell lysate $(50 \mu \mathrm{L})$ was incubated with substrate for $4 \mathrm{~h}$ at $37{ }^{\circ} \mathrm{C}$ before measurement of the absorbance at $405 \mathrm{~nm}$. Two additional controls, one without cell lysate and the other without substrate were included. Total protein was determined by the Coomassie Brilliant Blue method.

\subsection{Measurement of $N O$}

Nitrite production, measured by the Griess reaction, was used as a measure of NO production. Briefly, culture supernatant $(100 \mu \mathrm{L})$ was incubated with an equal volume of Griess reagent (1 part $0.1 \%$ naphthylethylenediamine, 1 part $1 \%$ sulfanilamide in $5 \% \mathrm{H}_{3} \mathrm{PO}_{4}$ ) in 96-well tissue culture plates for $10 \mathrm{~min}$ at room temperature in the dark [31]. The absorbance at $540 \mathrm{~nm}$ was determined using a microplate reader (SpectraMAX 340, Molecular Devices, Sunnyvale, CA, USA). The concentration of Nitrite was calculated as follows:

$$
\left[\frac{\text { sampleabs. }- \text { blank abs. }}{\text { slope of stdcuve }}\right] /(\mu \mathrm{L} \text { of sample })
$$

\subsection{Measurement of SOD}

Cells $\left(1 \times 10^{5}\right)$ were harvested and after treatment with OGD for $6 \mathrm{~h}$ and ActA plus OGD for $6 \mathrm{~h}$, the cells were washed twice with cold PBS and were lysed in ice-cold $0.1 \mathrm{M}$ Tris/HCl $(\mathrm{pH} 7.4$ containing $0.5 \%$ Triton X-100, $5 \mathrm{mM} \beta$-ME, $0.1 \mathrm{mg} / \mathrm{mL}$ PMSF). The cell lysates were centrifuged at $14,000 \mathrm{~g}$ for $5 \mathrm{~min}$ at $4{ }^{\circ} \mathrm{C}$ and the cell debris was discarded [32,33]. The total SOD activity in the supernatants (contain the cytosolic and mitochondrial fractions) were measured using the Superoxide Dismutase (SOD) Activity Assay Kit (Biovision k335-100, San Francisco, CA, USA) in accordance with the manufacturer's instructions. The percentage of SOD was calculated as follows: 


$$
\left(\mathrm{A}_{\text {control 1 }}-\mathrm{A}_{\text {control 2 }}-\mathrm{A}_{\text {sample }}\right) /\left(\mathrm{A}_{\text {control 1 }}-\mathrm{A}_{\text {control 2 }}\right) \times 100 \%
$$

\subsection{Statistics}

All data were presented as mean \pm S.E.M., based on data derived from three to six independent experiments. The square $\chi^{2}$ analysis was performed to evaluate the significance of inter-group differences. Student's $t$-test was used for single comparison between two groups. Two-way ANOVA using the Student-Newman-Keuls method was adopted for comparison of variables after treatment. $p<0.05$ was considered significant. All statistical calculations were performed using SigmaStat statistical software package (SPSS10.0, Chicago, IL, USA).

\section{Conclusions}

In conclusion, our results demonstrate that ActA protects PC12 cells in an OGD-deprivation model through the activation of the Smad pathway, the inhibition of NO production and the increased activation of SOD. Further investigation is required to understand fully the beneficial role of ActA in ischemic injury and could eventually lead to clinical interventions that will salvage brain cells that are at risk in ischemic cerebrovascular disease.

\section{Acknowledgments}

The project supported by the Natural Science Fund of Jilin Province in China (No. 201015181).

\section{References and Notes}

1. Paeme, S.; Moorhead, K.T.; Chase, J.G.; Lambermont, B.; Kolh, P.; D’Orio, V.; Pierard, L.; Moonen, M.; Lancellotti, P.; Dauby, P.C.; et al. Mathematical multi-scale model of the cardiovascular system including mitral valve dynamics. Application to ischemic mitral insufficiency. Biomed. Eng. Online 2011, 10, 86.

2. Barbarash, O.L.; Zykov, M.V.; Kashtalap, V.V.; Barbarash, L.S. Prevalence and clinical significance of multifocal atherosclerosis in patients with ischemic heart disease. Kardiologiia 2011, 51, 66-71.

3. Meschia, J.F.; Nalls, M.; Matarin, M.; Brott, T.G.; Brown, R.D., Jr.; Hardy, J.; Kissela, B.; Rich, S.S.; Singleton, A.; Hernandez, D.; et al. Siblings with ischemic stroke study: Results of a genomewide scan for stroke loci. Stroke 2011, 42, 2726-2732.

4. Foster, G.P.; Westerdahl, D.E.; Foster, L.A.; Hsu, J.V.; Anholm, J.D. Ischemic preconditioning of the lower extremity attenuates the normal hypoxic increase in pulmonary artery systolic pressure. Respir. Physiol. Neurobiol. 2011, 179, 248-253.

5. Ageta, H.; Tsuchida, K. Multifunctional roles of activins in the brain. Vitam. Horm. 2011, 85, 185-206.

6. Deli, A.; Kreidl, E.; Santifaller, S.; Trotter, B.; Seir, K.; Berger, W.; Schulte-Hermann, R.; Rodgarkia-Dara, C.; Grusch, M. Activins and activin antagonists in hepatocellular carcinoma. World J. Gastroenterol. 2008, 14, 1699-1709.

7. Kang, H.Y.; Shyr, C.R. Activins and cell migration. Vitam. Horm. 2011, 85, 129-148. 
8. Munz, B.; Tretter, Y.P.; Hertel, M.; Engelhardt, F.; Alzheimer, C.; Werner, S. The roles of activins in repair processes of the skin and the brain. Mol. Cell. Endocrinol. 2001, 180, 169-177.

9. Florio, P.; Gazzolo, D.; Luisi, S.; Petraglia, F. Activin A in brain injury. Adv. Clin. Chem. 2007, 43, 117-130.

10. Mukerji, S.S.; Rainey, R.N.; Rhodes, J.L.; Hall, A.K. Delayed activin A administration attenuates tissue death after transient focal cerebral ischemia and is associated with decreased stress-responsive kinase activation. $J$. Neurochem. 2009, 111, 1138-1148.

11. Liu, W.B.; Zhou, J.; Qu, Y.; Li, X.; Lu, C.T.; Xie, K.L.; Sun, X.L.; Fei, Z. Neuroprotective effect of osthole on $\mathrm{MPP}^{+}$-induced cytotoxicity in $\mathrm{PC1} 2$ cells via inhibition of mitochondrial dysfunction and ROS production. Neurochem. Int. 2010, 57, 206-215.

12. Chen, T.; Liu, W.; Chao, X.; Qu, Y.; Zhang, L.; Luo, P.; Xie, K.; Huo, J.; Fei, Z. Neuroprotective effect of osthole against oxygen and glucose deprivation in rat cortical neurons: Involvement of mitogen-activated protein kinase pathway. Neuroscience 2011, 183, 203-211.

13. Winkler, E.A.; Bell, R.D.; Zlokovic, B.V. Lack of Smad or Notch leads to a fatal game of brain pericyte hopscotch. Dev. Cell 2011, 20, 279-280.

14. Phillips, D.J.; Nguyen, P.; Adamides, A.A.; Bye, N.; Rosenfeld, J.V.; Kossmann, T.; Vallance, S.; Murray, L.; Morganti-Kossmann, M.C. Activin a release into cerebrospinal fluid in a subset of patients with severe traumatic brain injury. J. Neurotraum. 2006, 23, 1283-1294.

15. Wu, D.D.; Lai, M.; Hughes, P.E.; Sirimanne, E.; Gluckman, P.D.; Williams, C.E. Expression of the activin axis and neuronal rescue effects of recombinant activin A following hypoxic-ischemic brain injury in the infant rat. Brain Res. 1999, 835, 369-378.

16. Tong, J.L.; Nie, F.; Ran, Z.H.; Pan, C.Q.; Xu, X.T.; Zhu, M.M.; Xiao, S.D. Epigallocatechin gallate induces apoptosis in human hepatocellular carcinoma HepG2 cells via TGF/Smad signaling pathway. Zhonghua Zhong Liu Za Zhi 2009, 31, 646-650.

17. Yao, Q.; Pawlaczyk, K.; Ayala, E.R.; Styszynski, A.; Breborowicz, A.; Heimburger, O.; Qian, J.Q.; Stenvinkel, P.; Lindholm, B.; Axelsson, J. The role of the TGF/Smad signaling pathway in peritoneal fibrosis induced by peritoneal dialysis solutions. Nephron. Exp. Nephrol. 2008, 109, e71-e78.

18. Leonardi, A.; Di Stefano, A.; Motterle, L.; Zavan, B.; Abatangelo, G.; Brun, P. Transforming growth factor-beta/Smad-Signalling pathway and conjunctival remodelling in vernal keratoconjunctivitis. Clin. Exp. Allergy 2011, 41, 52-60.

19. Nakamura, M.; Ito, H.; Nakamura, Y.; Wate, R.; Kaneko, S.; Nakano, S.; Matsumoto, S.; Kusaka, H. Smad ubiquitination regulatory factor-2 in progressive supranuclear palsy. Neuropathol. Appl. Neurobiol. 2011, 37, 307-314.

20. Sachdev, U.; Cui, X.; Hong, G.; Namkoong, S.; Karlsson, J.M.; Baty, C.J.; Tzeng, E. High mobility group box 1 promotes endothelial cell angiogenic behavior in vitro and improves muscle perfusion in vivo in response to ischemic injury. J. Vasc. Surg. 2011, 55, 180-191.

21. Templin, C.; Luscher, T.F.; Landmesser, U. Stem and progenitor cell-based therapy approaches: Current developments on treatment of acute myocardial infarction and chronic ischemic cardiomyopathy. Herz 2010, 35, 445-456.

22. De Meyer, S.F.; Schwarz, T.; Schatzberg, D.; Wagner, D.D. Platelet glycoprotein Ibalpha is an important mediator of ischemic stroke in mice. Exp. Transl. Stroke Med. 2011, 3, 9. 
23. Shudo, Y.; Miyagawa, S.; Fukushima, S.; Saito, A.; Kawaguchi, N.; Matsuura, N.; Sawa, Y. Establishing new porcine ischemic cardiomyopathy model by transcatheter ischemia-reperfusion of the entire left coronary artery system for preclinical experimental studies. Transplantation 2011, 92 , e34-e35.

24. Park, D.; Joo, S.S.; Lee, H.J.; Choi, K.C.; Kim, S.U.; Kim, Y.B. Microtubule-associated protein 2, an early blood marker of ischemic brain injury. J. Neurosci. Res. 2011, 90, 461-467.

25. Li, C.T.; Zhang, W.P.; Lu, Y.B.; Fang, S.H.; Yuan, Y.M.; Qi, L.L.; Zhang, L.H.; Huang, X.J.; Zhang, L.; Chen, Z.; et al. Oxygen-glucose deprivation activates 5-lipoxygenase mediated by oxidative stress through the p38 mitogen-activated protein kinase pathway in PC12 cells. J. Neurosci. Res. 2009, 87, 991-1001.

26. Longxi, P.; Buwu, F.; Yuan, W.; Sinan, G. Expression of p53 in the effects of artesunate on induction of apoptosis and inhibition of proliferation in rat primary hepatic stellate cells. PLoS One 2011, 6, e26500.

27. Rao, V.; Balachandran, B.; Shen, H.; Logan, A.; Rao, L. In vitro and in vivo antioxidant properties of the plant-based supplement greens ${ }^{+}$. Int. J. Mol. Sci. 2011, 12, 4896-4908.

28. Han, P.; Kang, J.H.; Li, H.L.; Hu, S.X.; Lian, H.H.; Qiu, P.P.; Zhang, J.; Li, W.G.; Chen, Q.X. Antiproliferation and apoptosis induced by tamoxifen in human bile duct carcinoma QBC939 cells via upregulated p53 expression. Biochem. Biophys. Res. Commun. 2009, 385, 251-256.

29. Tara, S.; Takagi, G.; Miyamoto, M.; Kirinoki-Ichikawa, S.; Yamamoto, T.; Takano, H.; Takagi, I.; Yasutake, M.; Tabata, Y.; Mizuno, K. Novel approach to ischemic skin ulcer in systemic lupus erythematosus: Therapeutic angiogenesis by controlled-release basic fibroblast growth factor. Geriatr. Gerontol. Int. 2011, 11, 527-530.

30. Pieri, A.; Lopes, T.O.; Gabbai, A.A. Stratification with CHA2DS2-VASc score is better than CHADS2 score in reducing ischemic stroke risk in patients with atrial fibrillation. Int. J. Stroke 2011, 6, 466.

31. Peng, B.; Zhu, Y.; Cui, L.; Ni, J.; Xu, W.; Zhou, L.; Yao, M.; Chen, L.; Wang, J.; Wang, Y.; et al. Standard medical management in secondary prevention of ischemic stroke in China (SMART). Int. J. Stroke 2011, 6, 461-465.

32. Kim, J.S.; Yang, W.I.; Shim, C.Y.; Ha, J.W.; Chung, N.; Chang, H.J. Hemorrhagic transformation of ischemic stroke: Severe complications of prosthetic valve endocarditis. Korean Circ. J. 2011, 41, 490-493.

33. Kobusiak-Prokopowicz, M.; Jolda-Mydlowska, B.; Zubkiewicz, A.; Szymczak, M.; Mysiak, A.; Skalik, R. Impact of nebivolol on levels of serum nitric oxide, plasma von Willebrand factor and exercise stress testing parameters in hypertensive and ischemic heart disease patients. Cardiol. J. 2008, 15, 162-168.

Sample Availability: Samples of all compounds are available from the authors.

(C) 2012 by the authors; licensee MDPI, Basel, Switzerland. This article is an open access article distributed under the terms and conditions of the Creative Commons Attribution license (http://creativecommons.org/licenses/by/3.0/). 